\title{
REVIEW
}

\section{Carbon nanotubes: toxicological impact on human health and environment}

\author{
Gracian Tejral $^{1}$, Nagender Reddy Panyala ${ }^{1}$, Josef Havel ${ }^{1,2}$ \\ ${ }^{1}$ Department of Chemistry, Faculty of Science, Masaryk University, Brno, Czech Republic \\ ${ }^{2}$ Department of Physical Electronics, Faculty of Science, Masaryk University, Brno, Czech Republic
}

Received $25^{\text {th }}$ December 2008.

Revised $23^{\text {rd }}$ January 2009.

Published online $10^{\text {th }}$ March 2009.

\begin{abstract}
Summary
Nanotechnology is an emerging field of science which is producing nano-sized materials. Some nanomaterials are having a significant impact in health care. Of these, carbon nanotubes (CNTs) represent one of the most promising materials in the field of nano-science and technology. Their potential in industrial applications has brought them much attention and the wide spectrum of usage has made it imperative that the impact of CNTs on human health and the environment is investigated thoroughly. In addition to their various beneficial applications, there is a potential for hazardous effects on human health. For example, the potential hazards through inhalation of CNTs have not been sufficiently evaluated. CNTs produce reactive oxygen species (ROS) which are associated with diminishing cellular activities, such as a decrease in the mitochondrial membrane potential etc. This paper reviews the hazardous influence of CNTs on human health and the environment. Specifically, the effects of CNTs on lung toxicity, skin irritation and CNTs cytotoxicity on various cell lines are reviewed. Biomedical applications and biocompatibility of carbon nanotubes are also summarized.
\end{abstract}

Key words: carbon nanotubes; nano-materials; nanotechnology; cytotoxicity; lung toxicity; skin irritation; biocompatibility

\section{INTRODUCTION}

Carbon nanotubes (CNTs) discovered some fifteen years ago, are a very promising high technology material for both the present and the future. Even though they are still quite expensive, their unique properties make them popular, the result of which is that the worldwide production of nanotubes is

Josef Havel, Department of Chemistry, Faculty of Science, Masaryk University, Kotlářská 2, 61137 Brno, Czech Republic

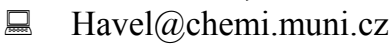

용 +420549494114

且 +420549492494 expected to be millions of tonnes per annum over the next ten years. It is also predicted that the price of carbon nanotubes will fall to approximately $\$ 8$ per $\mathrm{kg}$, which means that they will be available at about 10,000 times cheaper than their present price.

The expected emergence of carbon nanotubes in industry raises questions about their impact on health and the life cycle (persistence against degradation) of CNTs. Two studies on the life cycle of CNTs (for lithium-ion secondary batteries and synthetic textiles) were made by Köhler et al. (2008). A case study for using CNTs and their life cycle in the electronic sector was given by Bauer et al. (2008). Smart et al. (2006) summarized various carbon nanotubes toxicity effects according to the conclusions which were known up to 2005. Additionally, some biomedical applications of CNTs have been developed over the 
last three years. These can give us a new view on CNTs and their applications in medicine. This review summarizes the various toxicological effects of CNTs on human health and the environment.

Nanoparticles (NPs) are generally defined as particles less than $100 \mathrm{~nm}$ in diameter. The toxicity of nanoparticles mostly depends on two factors: their surface area and the reactivity or intrinsic toxicity of that surface (Donaldson et al. 2002). NPs represent a potential for toxic effects on human health and the environment. For example, a review on silver nanoparticles toxicity on human health and environment has been reported recently (Panyala et al. 2008). CNTs have features of both nanoparticles (NPs) and conventional fibres. So the NP and fibre toxicology paradigms are discussed in relation to CNTs.

\section{WHAT ARE CNTs?}

CNTs are a special form of carbon, where the chemical bonds of carbon form tubes from carbon atoms. Comparison of graphite, diamond, fullerene and CNT structures is given in Fig. 1. CNTs exist in two forms. Single-wall CNTs (SWCNTs) are containing only one tube in the CNT's structure. Multiwall CNTs (MWCNTs) are containing more than one concentric tube in the basic element of the CNT (Fig. 2 A, B). CNT material contains many very small tubes (fibres) which are created from carbon atoms and which have different lengths. The lengths are generally dependent on the synthesis time but are typically in the order of tens of microns, although significantly shorter and longer nanotubes have been made (Motta et al. 2005). The diameters of SWCNT fibres, which varied between about 0.7 and $3 \mathrm{~nm}$, are controlled by the size of the catalyst used in the
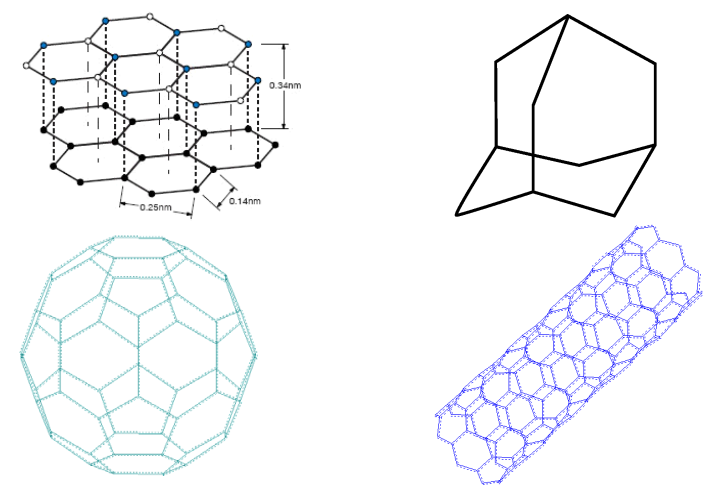

Fig. 1. Comparison of basic structural motifs of graphite, diamondoid (adamantane), fullerene and carbon nanotubes.
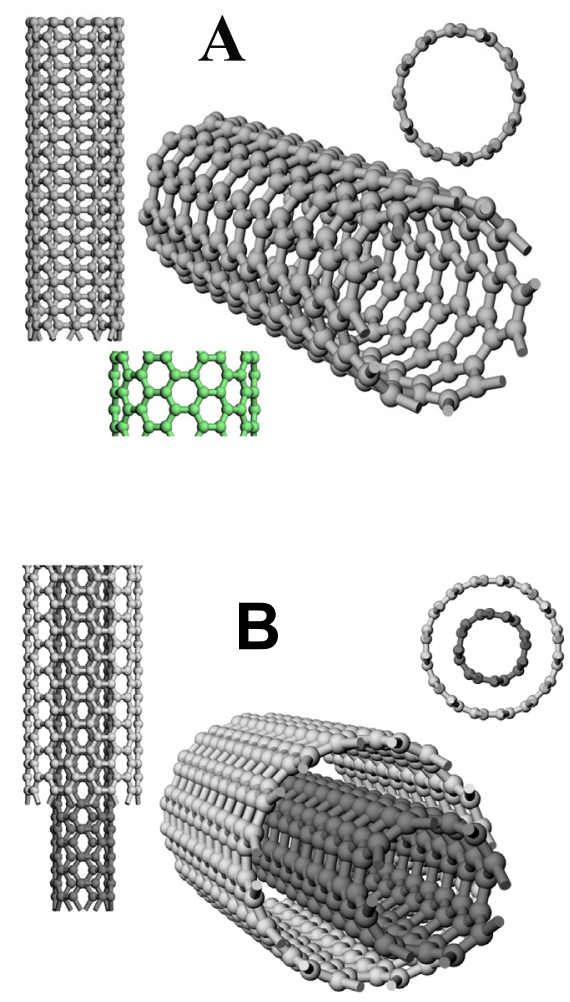

Fig. 2. Examples of CNTs structures. A, single wall CNT; B, multiwall CNT

production (Jorio et al. 2001). MWCNTs are generally in the range of 10 to $200 \mathrm{~nm}$ in diameter (Hou et al. 2003).

CNTs are mostly manufactured by electrical arc discharge (Sato et al. 2005), laser ablation and chemical vapour deposition processes (Donaldson et al. 2006). These processes involve thermally stripping carbon atoms off from carbon-bearing compounds in the presence of a metal catalyst. Co, $\mathrm{Fe}, \mathrm{Ni}$, and Mo are the most common metals used in CNTs production. Carbon nanotubes fabrication methods and their influence on properties of CNTs have been reported by Grobert et al. (2007).

Certainly, impurities from the synthesis of CNTs can have a potential influence on their toxicity. Even though postproduction processes remove the majority of these metal catalyst impurities, CNTs still contain residual metal up to $15 \%$ by mass (Jorio et al. 2001), and between $23 \%$ and 8\% (Kagan et al. 2006 and Wörle-Knirsch et al. 2006) respectively. By acid treatment, oxidation, annealing and filtering etc. it is possible to reduce the content of iron to as low as $0.23 \%$ (Kagan et al. 2006). Each CNT material contains some impurities, for example, carbon which 
is not a component of the CNT's structure. These impurities can be divided into two subclasses: amorphous or micro structured carbon and residual organic molecules. Purified nanotubes are likely to contain additional defects in the form of carboxylic acid $(-\mathrm{COOH})$ residues.

Pure CNTs are significantly un-reactive; e.g., SWCNTs must be heated to $500{ }^{\circ} \mathrm{C}$ before they burn in air (Zhang et al. 2002), but CNTs can be modified by the addition of different chemical groups on the carbon skeleton to significantly change many of their properties. Functionalization with polymer groups is used to enhance the solubility of CNTs. Functionalization with different groups is likely to result in different toxicities (Sayes et al. 2005) since the particle surface is important in interacting with biological systems. Besides modified (functionalized) carbon nanotubes, doped CNTs can also exist. In the case of doped CNTs, some carbon atoms from the CNT's skeleton are replaced with another chemical element, for example with boron (Mondal et al. 2007). In this way, the skeleton of CNTs is not formatted only from carbon (in contrast to modified CNTs). At present there are no experimental studies about the toxicity of doped CNT materials. Because the chemical reactivity of doped CNTs is not significantly different (if valence electrons will be saturated by the carbon skeleton), we can suppose that the toxicity of doped CNTs will not change. But there has been no experimental study of this problem to date.

\section{APPLICATIONS OF CNTs}

Carbon nanotubes have unique electrical, mechanical and thermal properties which gives them great potential for a wide variety of applications in industry. For example, CNTs can be as much as 10 times as strong as steel and 1.2 times as rigid as diamond (Walters et al. 1999, Yu et al. 2000). Carbon nanotubes are one of the major building substance in nanotechnology and have a big potential for applications in electronics, engineering, computer technologies, aerospace and other industries. Even elevators into space on the base of CNT composites has been proposed by the National aeronautics and space administration (NASA). However, it was Ciolkowski who first proposed a lift to a space station. Valcárcel et al. (2008) reviewed notes of using CNTs in analytical chemistry. CNTs can be used as carbon nanotube membranes, stationary phases in gas and liquid chromatography, pseudostationary phases in capillary electrophoresis in a new electrophoretic mode and for modified semiconductor transistors.

Analytical applications of carbon nanotubes has been reviewed by Trojanowicz et al. (2006). Various CNT applications are mentioned in 104 references at the end of this article. For example, an application of CNTs for gas sensors, voltammetry, enzymatic biosensors, immunosensors and DNA probes to mention but a few. Rao et al. (2007) summarized the possibilities of removal of divalent metal ions $\left(\mathrm{Cd}^{2+}\right.$, $\left.\mathrm{Cu}^{2+}, \mathrm{Ni}^{2+}, \mathrm{Pb}^{2+}, \mathrm{Zn}^{2+}\right)$ from an aqueous solution using various kinds of CNTs. The authors reported that most sorption works adopted either the Langmuir isotherm or the Freundlich isotherm (or both) for equilibrium sorption data correlation. Lu et al. (2007) studied CNTs as adsorbents for adsorption of natural organic matter in aqueous solutions. In their study they showed that CNTs are promising adsorbents for applications in water treatment.

\section{Biomedical applications and biocompatibility of CNTs}

Bio nanotechnology mostly investigates the interactions of nano-scale materials with the biological systems. A product should be considered as efficient and potent if it contains certain qualities like i) It has to enhance solubility and bioavailability of poorly soluble drugs ii) It should act as good carriers to improve both circulatory persistence and targeting of drugs to specific cells iii) It should be a good adjuvant for vaccine and drug delivery etc. Due to the high surface area and a propensity for surface functionalization, they can be used as carriers and this makes them useful for pharmaceutical nanodelivery of drugs and vaccines.

More and more applications of CNTs in the biomedical branch are being reported. For example, in the field of biosensors, the preparation of unique biomaterials, drug delivery (Bianco et al. 2005, Allen et al. 2004), protein delivery (Kam et al. 2004, 2005), vaccine delivery (Liu et al. 2005) and gene delivery (Panhuis 2003, Cai et al. 2005). A study of carbon nanotubes biocompatability was reported (Chlopek et al. 2006, Koyama et al. 2006).

Klumpp et al. (2006) summarized applications of carbon nanotubes for the delivery of drugs. Strategies for solubilization are described and carrier systems for drugs, peptides, proteins and nucleic acids are discussed. Deng et al. (2007) used [14C-taurine]multi-walled CNTs (MWCNTs) as tracers for drugs. Taurine was chosen for its very good solubility. The authors showed the bio distribution and translocation pathways of MWCNTs in mice by three different routes. After the mice were intravenously injected, 
MWCNTs predominately accumulated in the liver and were retained for a long time. Transmission electron micrographs clearly revealed the remarkable entrapment of MWCNTs in hepatic macrophages (Kupffer cells). The biological index examinations indicated low liver acute toxicity of MWCNTs. Some positive aspects of MWCNTs being used as a drug nano-vehicle are also discussed.

Foldvari and Bagonluri (2008a,b) reviewed CNT functionalization for pharmaceutical applications and experimental results from the delivery of small molecules using CNTs, the delivery of therapeutic proteins, peptides and genes by CNTs, delivery of vaccines by CNTs and using CNTs as matrices for compounds that stimulate neuron growth. In vitro and in vivo CNT toxicity were discussed. The synthesis, purification, and analysis of CNTs related to their pharmaceutical properties and quality control were summarized.

Wang et al. (2007) provided the first in vivo testing evidence that pure bulk CNTs are not a strongly inflammatory substance and have no toxicity for bone regeneration. Their study was the first successful experiment to consolidate CNTs without binders, and may provide an effective method for CNT monolith synthesis as well as demonstrating that a binder less carbon nanotubes material with a strength matching that of bone could be a candidate for bone substitute material and a bone tissue engineering scaffold material.

Balani et al. (2007) applied CNTs in hydroxyapatite (HA) coating using plasma spraying to improve the fracture toughness (by 56\%) and enhance crystallinity (by 27\%), and culturing human osteoblast hFOB 1.19 cells onto a CNT reinforced HA coating to bring out its biocompatibility with living cells. Unrestricted growth of human osteoblast hFOB 1.19 cells has been observed near the CNT regions assisted by CNT surfaces to promote cell growth and proliferation.

\section{CNT applications in the determination of mycotoxins}

CNTs' unique properties with large surface areas make them attractive for bio sensing. CNTs play a major role in the determination of mycotoxins which are fungal metabolites. These mycotoxins cause food poisonings when we consume fungally contaminated food commodities. It was reported that MWCNTs modified with aflatoxin-detoxifizyme (ADTZ) have been used to construct a novel biosensor to examine the response characteristics of toxic mycotoxins such as sterigmatocystine, which is a carcinogenic aflatoxin (Yao et al. 2006). Nowadays the application of biosensors is playing a key role in the detection of these mycotoxins (Pohanka et al. 2007). In the construction of these biosensors, carbon nanotubes have been used (Yao et al. 2006). It was recently reported that CNTs have been used in optical immuno detection of Staphylococcal enterotoxin B (SEB). They examined whether CNTs can enhance the detection sensitivity of ELISA assays. For this purpose, a CNT immunosensor was developed to detect this enterotoxin. In this process anti-SEB antibodies were immobilized on to a CNT surface through electrostatic adsorption and then an antibodynanotubes mixture was bound onto a polycarbonate film. Here "sandwich type" ELISA assays were used for the detection of SEB on the polycarbonate film. It was concluded that CNTs increased the sensitivity of the immunosensor by at least 6-fold (Yang et al. 2008). There is plenty of literature where it has been reported that these CNTs have been used for the detection of various mycotoxins (Yu et al. 2006, Wei et al. 2007). Recently, Elosta et al. (2007), investigated the MALDI TOF mass spectrometric analysis of selected mycotoxins in barley.

\section{CYTOTOXICITY OF CNTs}

Even though CNTs are used in the above mentioned beneficial applications, they also represent a threat of adverse effects on human health. In the area of this CNT toxicity primarily lung toxicity, skin irritation, cardiovascular toxicity, and cytotoxicity effects have been studied. Different dimensions of the nano particles and the presence of impurities in the resultant product can both have a definite effect on the toxicity of CNTs. The influence of metal impurities on the biological activity of CNTs is presumed by Pulskamp et al. (2007). Kagan et al. (2006) and Wörle-Knirsch et al. (2006) consider the possibility that the acute toxic effects are heavy metal-induced effects and do not have a connection with carbon nanotubes toxicity. Similar conclusions were mentioned by Pulskamp et al. (2007). On the other hand, pathological effects induced directly by CNTs are considered by some other authors as given below. Unfortunately the precise specifications of the CNTs are absent in some previous works. Tamura et al. (2004) conducted a brief investigation into the cytotoxic effect of purified CNTs on neutrophils isolated from human blood. Purified CNTs significantly increased super-oxide anion and tumour necrosis factor-alpha (TNF- $\alpha$ ) production after contact with the cells for 1 hour compared to the controls, while cell viability was observably decreased. 
Monteiro-Riviere et al. (2005) tested MWCNT products with doses of $0.1,0.2$, and $0.4 \mathrm{mg} / \mathrm{ml}$ of CNTs without a catalytic metal with an incubation time up to 48 hours. Uptake of particles by the human embryonic kidneys was demonstrated by transmission electron microscopy. The cells in the $0.4 \mathrm{mg} / \mathrm{ml}$ culture were found to release the pro-inflammatory cytokine interleukin-8 (IL-8) in a time-dependent fashion. Monteiro-Riviere and Inman (2006) discussed the various controversial toxic effects of CNTs on skin.

Jia et al. (2005) exposed alveolar macrophages to SWCNTs (1.4 nm in diameter, synthesized by electric arc-discharge and purified to 90\%), MWCNTs (10-20 nm in diameter, synthesized via CVD and purified to $>95 \%$ ) and $\mathrm{C}_{60}$ fullerenes (synthesized via electric arc-discharge and purified to $99.9 \%$ ) for 6 hours. SWCNTs exhibited the most cytotoxic response, although both SWCNTs and MWCNTs demonstrated decreased cell viability.

Manna et al. (2005) examined the toxicity of SWCNTs on human keratinocyte cells and signaling mechanism in keratinocytes upon exposure to SWCNTs. They have concluded that exposure to SWCNTs is associated with increased oxidative stress and inhibition of cell proliferation. Murr et al. (2005) performed viability assays on a murine macrophage cell line and they found that the cytotoxicity of commercially available SWCNTs and MWCNTs revealed a strong concentration relationship and toxicity for all the carbon nanotube materials. Comparison to the asbestos nanotubes and black carbon standards was done.

Pulskamp et al. (2007) incubated human lung cells with commercial SWCNTs and MWCNTs, carbon black and quartz as reference particles as well as acid-treated SWCNTs with reduced metal catalyst content. They have concluded that incubation with all CNT products did not produce any observable acute toxicity on cell viability. However, a dose- and timedependent increase of intracellular reactive oxygen species and a decrease of the mitochondrial membrane potential with the commercial CNTs were observed. With the purified CNTs no such effect was observed. The conclusion was made that metal traces associated with the commercial nanotubes are responsible for these biological effects. The same conclusion, i.e. CNTs without amorphous carbon residues and metal impurities do not induce oxidative stress in human epithelial lung cells, was made by Pulskamp et al. (2007).

In a recent study by Wick et al. (2007), the cytotoxic effects of well-dispersed CNTs were compared with that of conventionally purified ropelike agglomerated CNTs and asbestos as a reference.
While suspended CNT-bundles were less cytotoxic than asbestos, rope-like agglomerates induced more pronounced cyto-toxic effects than asbestos fibres at the same concentrations. The study underlines the need for thorough material characterization prior to toxicological studies and corroborates the role of agglomeration in the cytotoxic effect of nanomaterials. The initial study by Huczko et al. (2001), investigated the effects of CNTs on the pulmonary function of guinea pigs. No indication of lung toxicity was found, despite further studies finding evidence of lung inflammation and granuloma formation.

\section{Effect of agglomeration and dispersion on CNT toxicity}

For more technical applications, purified CNTs are required. There are some purification treatments, like acidic and optional oxidation treatments, for CNT purification that remove most of the impurities. But through these treatments, there may be a chance of altering the chemical functionality and dispersion stability. Because of their geometry and hydrophobic surface CNTs have a tendency to form agglomerates with a bundle like form.

There are many methods for the dispersion of CNTs such as using organic solvents (Ausman et al. 2000) or using a series of surfactants (Moore et al. 2003) and ultrasonication. Surface functionalization of CNTs makes them more toxic than the normal CNTs.

Wick et al. (2007), examined how the degree of dispersion and agglomeration affects the CNTs cytotoxicity. A comparative study of the cytotoxicity of CNTs was also done with the cytotoxicity of asbestos as a reference, particularly as plenty of reports on the potential toxic effects of asbestos on animals (Murr 2008) have been reported.

Wick et al. (2007) concluded that CNT agglomerates evoke similar effects on cell morphology and cell performance as the asbestos reference.

Their light microscopic studies revealed that CNT interaction with the mesothelioma cell line (MSTO$211 \mathrm{H})$ caused morphological changes in the cell lines. It was noticed that these CNT agglomerates showed negative effects on cell proliferation and cell viability.

It was reported that acidic and oxidative treatments of CNTs modify the surface of CNTs which leads to the agglomeration of CNTs (Johnston et al. 2005). So the degree of dispersion and agglomeration is able to modify CNT toxicity (Wick et al. 2007). 


\section{Exposure methods of CNTs}

\section{Occupational exposure}

It has been reported that during CNTs handling there is a release aerosols into the atmosphere (Maynard et al. 2004). Generally these aerosols have 20-200 nm diameters and $10^{3}-10^{6} \mathrm{~nm}$ length. Also they have different shapes such as straight, bent, curled, partly flexible and partly rigid and they may be appear as singly or as clumps or ropes (Donaldson et al. 2006).

According to Maynard et al. (2004), their experimental studies indicated that SWCNT production methods produce different types of aerosols. It was also noticed that glove deposits of SWCNTs during the handling of SWCNTs were estimated at between 0.2 and $6 \mathrm{mg}$ per each hand and they could remain in hands for longer periods. These accumulated clumps may cause dermal exposure and health risks. These large SWCNTs containing clumps had a tendency to become airborne.

These CNTs contain some impurities like nickel, which is the predominant carcinogenic agent. Even cleaning the production chambers of these CNTs can emit this type of aerosol. This waste carries CNTs into the waste water stream, which may destroy aquatic environmental bodies.

\section{Environmental mediated exposure}

Due to the huge numbers of applications of CNTs, substantial production of CNTs can be expected in the industrial sectors. This may result in the emission of huge amounts of CNTs into the environmental bodies such as ground water, lakes, air and soil etc. These CNTs are one of the least biodegradable materials which, in pristine form, are insoluble in water and are lipophilic in nature. So by the over accumulation of these lipophilic CNTs they may enter and alter the food chain (Helland et al. 2007).

From here onwards, we will discuss the different individual adverse effects of SWCNTs and MWCNTs.

\section{Toxic effects of SWCNTs}

Single walled carbon nanotubes are showing potential toxic effects on human health and the environment. In the synthesis process of SWCNTs there are so many residual catalyst metals, such as $\mathrm{Co}, \mathrm{Ni}, \mathrm{Mo}$ and $\mathrm{Fe}$, present even after the post purification treatments. These heavy metals present a toxic threat to biological cells, which has been well known in the metal working industries for centuries. But the molecular mechanisms underlying this pathologic behaviour have not yet been fully understood.

\section{Toxic effects on lung cells and the pulmonary} system

As per existing literature (Pulskamp et al. 2007), it was reported that contact with SWCNTs will cause acute toxic affects and apoptosis in the human lung epithelial cells. For this purpose human alveolar epithelial cell lines (A549) have been chosen for observation of the apoptosis, i.e., programmed cell death by contact with CNTs. It was also reported that CNTs can liberate reactive oxygen species (ROS), peroxy nitrates $\left(\mathrm{ONOO}^{-}\right)$and superoxide anions $\left(\mathrm{O}_{2}^{-}\right)$. It has been assumed that there are two independent mechanisms existing in cells to produce ROS on exposure to CNTs. The first one is the amorphous carbon that is responsible for the production of high amounts of ROS. The second one is the metal impurities which are present in CNTs that lead to delayed production of ROS inside the biological cells, which may also cause also mitochondrial injury.

\section{Toxicity on human blood cells}

It was reported that there was a potential toxic effect on human peripheral blood lymphocyte (HPBL) cells with the interaction of SWCNTs. According to Zeni et al. (2008), it was noticed that there was a decrease in the cell number after treating these HPBL cells with SWCNTs for 24-72 hours. In this study, cell growth, viability, apoptosis and metabolic activity were all evaluated. For this evaluation, they have used SWCNT concentrations ranging from $1-50 \mu \mathrm{g} / \mathrm{ml}$.

\section{Toxic effects on human astrocytoma cells}

Pure SWCNTs do not show any cytotoxic effects on human health. But surface modified SWCNTs do show significant toxic effects on human cells. Cytotoxicity of functionalized SWCNTs depends on the functional groups present on the surface of the nanotubes and the chemicals attached to these functional groups, according to Dong et al. (2008), who have examined SWCNTs-surfactant conjugate's cytotoxicity on human astrocytoma $1321 \mathrm{~N} 1$ cells. In this study, it was demonstrated that these surfactants like sodium dodecyl benzene sulphate (SDBS) and SDS etc. were enhancing the cytotoxicity of SWCNTs. Here in this experimental study, cell viability and cell proliferation were examined. It was concluded that these SDS/CNT and SDBS/CNT conjugates were showing adverse affects on the cells and this toxicity was mainly dependent on the concentration of the surfactant used.

Toxic effects on human fibroblast cells SWCNT interaction causes cellular apoptosis or necrosis in human fibroblast cells, according to Tian 
et al. (2006), who examined the toxic effects of refined SWCNTs i.e., without catalytic transitional metals on the fibroblast cells. It was concluded that there was a strong increase of cellular apoptosis and necrosis in the cells. SWCNTs with transitional metals can also induce reactive oxygen species (ROS) and oxidative stress.

\section{Effect of SWCNTs on human embryonic kidney (HEK293) cells}

Cui et al. (2005) investigated SWCNTs cytotoxicity showing that SWCNTs inhibited human embryonic kidney (HEK293) cells by inducing apoptosis and decreasing cellular adhesion ability. HEK293 cells were cultured in a media containing concentrations of SWCNTs ranging from $0.78 \mu \mathrm{g} / \mathrm{ml}$ to $200 \mu \mathrm{g} / \mathrm{ml}$ and these cells were tested for a variety of functions, including adhesion ability and protein secretion.

\section{Toxic effects of SWCNTs in animals}

Lam et al. (2004) investigated the pulmonary toxicity of three batches of SWCNTs in mice. Investigators found that all three SWCNT products induced dosedependent lung lesions, characterized by interstitial granulomas, regardless of the levels of metal impurities. They strongly believed that the presence of CNTs resulted in granuloma formation, although they noted that the SWCNTs containing Ni produced a higher mortality rate. The study also concluded that SWCNTs were more toxic than carbon black, and CNTs containing Ni were more toxic than quartz.

Warheit et al. (2004) studied the lung toxicity of SWCNTs in rats. This study exposed 8 -week old male rats to 1 or $5 \mathrm{mg} / \mathrm{kg}$ of unrefined SWCNTs. Histological examination of the exposed animals identified a series of non-dose dependent multi-focal granulomas. The granulomas were non-uniform in distribution and not progressive after 1 month.

In the study of Shvedova et al. (2005) it was found that the pharyngeal aspiration of mice exposed to SWCNTs led to a dose-dependent increase in inflammatory markers at 1-3 days post exposure, granuloma formation and progressive interstitial fibrosis and alveolar wall thickening up to 60 days post exposure.

The interaction with SWCNTs leads to adverse effects on the cardiovascular system in mice. According to Li et al. (2007), it was reported that SWCNTs can lead to the mitochondrial DNA (mtDNA) damage at 7, 28, and 60 days after exposure. This also led to the formation of increased protein carbonyls in aortic tissues. It causes alterations in the endothelial activities leading to a series of events including vasoconstriction, increased adhesiveness resulting in inflammatory cell infiltration, and platelet thrombus formation. All these sequential alterations in the cardiovascular system lead to atherosclerosis. This pulmonary SWCNTs exposure may induce cardiovascular effects either directly or indirectly through mitochondrial oxidative perturbations, which can result in altered homeostasis. These SWCNTs induced lung pathophysiological responses are associated with the deposition of agglomerates of SWCNTs, which will translocate from the lungs to the systemic circulation causing direct cardiovascular endothelial dysfunction (Li et al. 2007).

\section{Skin irritation by SWCNTs}

The effect of SWCNTs on skin cells has been investigated by Shvedova et al. (2003) who observed the formation of free-radical species, the accumulation of peroxidative products, the reduction of total sulphhydryls and a decrease in the content of vitamin E. These effects were assigned to the iron impurities that were present in the CNTs.

\section{Effect of SWCNTs on aquatic environment}

The large surface area of CNTs may be one reason for the adherence of pollutants and the transport of them throughout the environment (Kleiner and Hogan 2003). According to Yang et al. (2006), there is a high adsorption capacity of polycyclic aromatic hydrocarbons (PAHs) with the different types of CNTs. This indicates that CNTs have a potential affect on the fate of these PAHs. According to Oberdörster et al. (2006), it was notified that SWCNTs can be ingested by the suspension feeding worm Caenorhabditis elegans, but is not digested in the digestive tract of this worm. But SWCNTs can be moved to food chain as these worms are consumed by benthivores. So there may be a chance of altering the food chain in this environment by these SWCNTs. According to Oberdörster et al. (2005), who described bioavailability of SWCNTs to aquatic organisms as both water solubilized and unsolubilized forms, which were detected in the digestive tract of fish exposed to SWCNTs. Oberdörster et al. (2006) reported ingestion of lipophilic pristine CNTs by microbial communities and plant roots. Consequently, there may be a chance of accumulation of these CNTs in plant tissues.

Cheng et al. (2007) examined the impact of SWCNTs on the aquatic environment. The toxic effect on the development of zebra fish embryos was examined. It was concluded that exposure to SWCNTs induced a significant hatching delay in zebra fish embryos. Molecular and cellular analysis showed that the embryonic development of the exposed embryos was affected at the concentration of 
$360 \mathrm{mg} / \mathrm{L}$ of SWCNTs. So these studies suggest that SWCNTs have great hazardous effects on aquatic life.

\section{Toxic effects of MWCNTs}

There is limited information on how MWCNTs can react with living cells. So some experimental examinations have been done to estimate the toxic effects on MWCNTs on living cells. Here we are demonstrating various toxic effects of MWCNTs in different fields.

\section{Toxic effects on keratinocytes}

Exposure of MWCNTs to keratinocytes can lead to potential toxic effects. According to Monteiro-Rivere et al. (2005), these MWCNTs changed the keratinocyte cell morphology when they were exposed to MWCNTs. They found these MWCNTs within the free cytoplasm, lying close to the nucleus and appeared to pierce the nuclear membrane. These nanotubes were primarily located within the intracytoplasmic vacuoles of the keratinocytes. They also cause dermal irritation in humans. It was concluded that this irritation response is mainly due to the presence of the iron catalyst which was still on the surface of nanotubes even after several post purification treatments.

According to Witzmann et al. (2006), exposure to these MWCNTs can alter the protein expression in human kearatinocytes. For this examination, human epidermal keratinocytes (HEKs) were used. Compared with the controls, exposure to these MWCNTs altered the expression of 36 proteins after 24 hours exposure and 104 proteins after 48 hours exposure. By exposure to nanotubes, the levels of pro inflammatory cytokines such as IL-8 and IL-1B can be elevated and this in turn can initiate an inflammatory response at $0.4 \mathrm{mg} / \mathrm{ml}$ dose of MWCNTs.

\section{Toxic effects on alveolar murine macrophages}

Alveolar macrophages play a key role in removing inhaled particulate substances from the alveolar surface. It is necessary to address their biological response to CNTs in-depth. Once inhaled and deposited on the alveolar surface, these CNTs are either scavenged by macrophages or translocated through the lung tissues (Oberdörster et al. 2005). According to Hirano et al. (2008), who have done experimental examinations to investigate how MWCNTs can exert their toxicity on macrophage cells, the MWCNTs passionately associate with the macrophages and cause necrosis to macrophages injuring the plasma membrane.

For this examination mouse macrophage cell lines were used and these cells were cultured with various concentrations of MWCNTs for 16-32 hours. A concentration dependent reduction of the viability of murine macrophages after 16, 24 or 32 hours exposure was observed. A decrease in the viability with increasing the time of MWCNT exposure and concentration was noticed. Electron microscopy was used to show how these MWCNTs killed murine macrophage. The plasma membrane disruption by exposure to these MWCNTs was observed (Hirano et al. 2008).

\section{Lymphocyte apoptosis by MWCNT exposure}

MWCNTs can induce apoptosis of T lymphocytes. These CNTs can reduce the cell viability. The affect of CNT treatment was both dose and time dependent. According to Bottini et al. (2006), both pristine and oxidized CNTs can induce apoptosis in freshly isolated human $\mathrm{T}$ lymphocytes and also that surface functionalized CNTs, such as oxidized CNTs, are more toxic than pristine CNTs. The paper also discussed additional adverse effects of MWCNTs such as the alteration of many genes, increased metabolism, cytoskeletal rearrangements, activation of effectors' function cells of the T cell (e.g., killing of target cells or secretion of cytokines) and the initiation of an immune response.

\section{Lung toxicity in rats by MWCNTs}

Preliminary studies showed that unprocessed CNTs are very light and they could become airborne. Therefore they can reach the lungs and then damage lung tissue. Liu et al. (2008), have done a critical examination of acute lung toxicity of intratracheally instilled MWCNTs in rats. In this experiment, a rat lung was intratracheally instilled with $0,1,3,5$, and $7 \mathrm{mg} / \mathrm{kg}$ of MWCNTs. After 3 months of exposure, these rats were killed by cervical vertebra displacement. Then histo-pathological studies were carried out to evaluate inflammation infection of the lung in all CNT-exposed rats. The only general observation was an increase in weight of the rats with increasing age. But in the rats with a high dosage of CNTs, prominent inflammation in the cells such as macrophages, lymphocytes, neutrophils, eosinophils, and other inflammation cells was evident. Also a crack in the lung alveolus at 3,5 , and $7 \mathrm{mg} / \mathrm{kg}$ of CNTs dosage was observed. These MWCNTs can be deposited even after exposure of CNTs for 3 months and they can change the ultra structural features of the lung tissue cell (Liu et al. 2008).

The over accumulation of these CNTs can cause lung inflammation, formation of granuloma, and also fibrosis. Huczko et al. (2005), investigated the toxic effects of five different MWCNT samples. The 
animals were tested for lung resistance and histopathological examination at 90 days. Unlike the preliminary study, significant evidence of pulmonary toxicity was observed. Muller et al. (2005) and Muller et al. (2006) followed the effect of MWCNTs on the pulmonary function of rats in 60 days of experiments. Asbestos and carbon black were used for comparison. A dose-dependent inflammation, granuloma formation and fibrotic reactions to CNTs were observed. According to Muller et al. (2006), this inflammation was not transient, persisting for the whole 60 days of experiment.

Muller et al. (2008), examined how MWCNTs induce lung inflammation as well as fibrosis in rats. Any genotoxic potentiality of these CNTs in the same animals was also investigated. The CNT genotoxic effects on rat lung cells, especially in type II pneumocytes (AT-II), which are the progenitor cells of the alveolar epithelium were also observed. In this experiment, two complimentary approaches, based on the micronucleus assay, were used in vivo and in vitro to characterize the genotoxic effect of MWCNTs. It was concluded that these MWCNTs have potential adverse effects on rat lung epithelial cells. They also reported that MWCNTs can induce mutations in lung cells and further characterization is needed to understand the basic mechanism of MWCNTs toxic effect on mutagenic activity (Muller et al. 2008). On the other hand, Colvin et al. (2003) reported that the pulmonary toxicity of CNTs was not obvious as granulomas were not commonly observed in rat lungs instilled with CNTs (Colvin et al. 2003).

\section{CONCLUSIONS}

There are various types of CNTs with unique physical and chemical properties and having different exposure routes. It follows from the literature that surface functionalisation of CNTs makes them more toxic than purified CNTs. There are different factors which influence the toxicity of CNTs such as disagglomeration, dispersion of CNTs, surfactant concentrations etc. Also CNTs may cause different environmental health effects depending on the life cycle of the product in the environment. Nanoparticulate impurities, such as catalytic trace metals which still remain on the surface of the CNTs even after several post-purification treatments, can influence the toxicity of CNTs. The post-purification methods can alter the different properties of CNTs such as length, purity, degree of aggregation, wall structure and surface functionalization. These properties along with other properties such as mobility in the environment, chemical reactivity, persistence, bioavailability, and particle sizes etc. are thought to be relevant determining toxicological factors. The impact of engineered CNTs differs from the natural occurring CNTs, mostly dependent on the technical application and circumstances of release.

Coming to the exposure related issues of CNTs, their emissions mostly depend on their application, product life cycle in the environment, fabrication conditions, further processing, product usage and their disposal into the environment. In the case of occupational exposure, handling procedures of CNTs such as bottling, packing, safety cleaning of instillations, leakages and accidents and waste conditioning may be the major exposure routes in work places. Waste materials such as gloves and worn filter pads could be dispersing CNTs into the environment. So it is critical that further investigation into CNT exposure routes is undertaken. Therefore, drawing attention to the exposure scenarios of CNTs could be very useful when conducting any toxicological studies.

The fate of CNTs in the environmental bodies may differ on their specific properties such as surface chemistry, oxidative potential and electrical properties. Studies have shown that functionalization and aggregation of CNTs can alter the food chain in the environmental bodies. So it could be useful to know the type and form of CNTs that could be released into the environmental bodies such as lakes, rivers etc. Other factors in the environment such as $\mathrm{pH}, \mathrm{UV}$ light, redox potential, different toxins can alter the CNTs functionality and their fate in the environment. Therefore, to some extent, it would be possible to predict and control the effects caused by different CNTs in the environment.

It would seem that the question of toxicity of CNTs is still not completely answered. However, one thing is clear. Toxicity of CNTs is closely related to their producing impurities and maybe with their mass fragment constitution. Unfortunately methods of CNT fraction analysis still need optimization and development. Toxicity studies do not have reference to this information. However, Hassellov et al. (2008) reviewed methods that can be appropriate for the analysis and characterization of nanomaterials. Methodological aspects are discussed in relation to the fields of nanometrology, particle size analysis and analytical chemistry. Differences in both the measurements (length, radius, aspect ratio, etc.), and the type of average or distributions afforded by the specific measures are compared. The strengths of single particle methods, such as electron microscopy and atomic force microscopy, with respect to imaging, shape determinations and application to 
particle process studies are discussed, together with their limitations in terms of counting statistics and sample preparation.

From the CNT toxicological profile point of view, these compounds may cause oxidative stress, inflammation, cell damage, adverse effects on cell proliferation, long term perspective pathological effects such as formation of granulomas, fibrosis, etc. These effects have been also observed as dose and time dependent. So it is crucial that an investigation into the pathogenicity and cytotoxicity of CNTs is undertaken as quickly as possible. The significant considerations between the inter-disciplinary scientific fields such as material and surface science to biology have been discussed above. Integrating the nano-toxicological profile of different kinds of CNTs with a life cycle perspective must therefore be a prerequisite for the development of nano technologically based applications in a safe manner.

Concluding, todate many studies have been done on the effects of CNTs on human health and environment. But it appears that health and environmental impacts have not been sufficiently investigated till now and therefore, more deep research is needed.

\section{ACKNOWLEDGEMENTS}

This work was sponsored by the Grant Agency of the Czech Republic, project no. 525/06/0663 and 202/07/1669, Ministry of Education, Youth and Sports of the Czech Republic, project MSM0021622411 and LC 06035.

\section{REFERENCES}

Allen TM, Cullis PR: Drug delivery system: Entering the main stream. Science 303:1818-1822, 2004.

Ausman KD, Piner R, Lourie O, Ruoff RS: Organic solvent dispersions of single-walled carbon nanotubes: Toward solutions of pristine nanotubes. J. Phys. Chem. B 104:8911-8915, 2000.

Balani K, Anderson R, Lahaa T, Andaraa M, Terceroa J, Crumplerb E, Agarwala A: Plasmasprayed carbon nanotube reinforced hydroxyapatite coatings and their interaction with human osteoblasts in vitro. Biomaterials 28:618-624, 2007.

Bauer C, Buchgeister J, Hischier R, Poganietz WR, Schebek L, Warsen J: Towards a framework for life cycle thinking in the assessment of nanotechnology. J. Cleaner Production
16:910-926, 2008.

Bianco A, Kostarelos K, Partidos CD, Prato M: Biomedical applications of functionalised carbon nanotubes. Chem. Commun. (Camb.) 5:571-577, 2005.

Bianco A, Kostarelos K, Prato M: Applications of carbon nanotubes in drug delivery. Curr. Opin. Chem. Biol. 9:674-679, 2005.

Bottini M, Bruckner S, Nika K, Bottini N, Bellucci S, Magrini A, Bergamaschi A, Mustelin T: Multiwalled carbon nanotubes induce $\mathrm{T}$ lymphocyte apoptosis. Toxicol. Lett. 160:121-126, 2006.

Cai D, Mataraza JM, Qin ZH, Huang Z, Huang J, Chiles TC, Carnahan D, Kempa K, Ren Z: Highly efficient molecular delivery into mammalian cells using carbon nanotube spearing. Nat. Methods 2:449-454, 2005.

Cheng J, Flahaut E, Cheng SH: Effect of carbon nanotubes on developing zebra fish (Danio rerio) embryos. Environ. Toxicol. Chem. 26:708-716, 2007.

Chlopek J, Czajkowska B, Szaraniec B, Frackowiak E, Szostak K, Beguin F: In vitro studies of carbon nanotubes biocompatibility. Carbon 44:1106-1111, 2006.

Colvin VL: The potential environmental impacts of engineered nanomaterials. Nat. Biotechnol. 21:1166-1170, 2003.

Cui D, Tian F, Ozkan CS, Wang M, Gao H: Effect of single wall carbon nanotubes on human HEK293 cells. Toxicol. Lett. 155:73-85, 2005.

Deng X, Jia G, Wang H, Sun H, Wang X, Yang S, Wang T, Liu Y: Translocation and fate of multiwalled carbon nanotubes in vivo. Carbon 45:1419-1424, 2007.

Donaldson K, Aitken R, Tran L, Stone V, Duffin R, Forrest G, Alexander A: Carbon Nanotubes: A review of their properties in relation to pulmonary toxicology and workplace safety. Toxicol. Sci. 92:5-22, 2006.

Donaldson K, Tran CL: Inflammation caused by particles and fibres. Inhal. Toxicol. 14:5-27, 2002.

Dong L, Joseph KL, Witkowski CM, Craig MM: Cytotoxicity of single-walled carbon nanotubes suspended in various surfactants. Nanotechnology 19:art. no. 255702, 2008.

Elosta S, Gajdošová D, Havel J: MALDI TOF MS of selected mycotoxins in barley. J. Appl. Biomed. 5:39-47, 2007.

Foldvari M, Bagonluri M: Carbon nanotubes as functional excipients for nanomedicines: I. pharmaceutical properties. Nanomed. Nanotechnol. Biol. Med. 4:183-200, 2008. 
Foldvari M, Bagonluri M: Carbon nanotubes as functional excipients for nanomedicines: II. drug delivery and biocompatibility issues. Nanomed. Nanotechnol. Biol. Med. 4: 173-182, 2008.

Grobert N: Carbon nanotubes - becoming clean. Materials Today 10:28-35, 2007.

Hassellov M, James Readman JW, Ranville JF, Tiede $\mathrm{K}$ : Nanoparticle analysis and characterization methodologies in environmental risk assessment of engineered nanoparticles. Ecotoxicology 17:344-361, 2008.

Helland A, Wick P, Koehler A, Schmid K, Som C: Review: Reviewing the environmental and human health knowledge base of carbon nanotubes. Environ. Health Perspect. 115:1125-1131, 2007.

Hirano S, Kanno S, Furuyama A: Multi-walled carbon nanotubes injure the plasma membrane of macrophages. Toxicol. Appl. Pharmacol. 232:244-251, 2008.

Hou PX, Xu ST, Ying Z, Yang QH, Liu C, Cheng HM: Hydrogen adsorption/desorption behavior of multi-walled carbon nanotubes with different diameters. Carbon 41:2471-2476, 2003.

Huczko A, Lange H, Bystrzejewski M, Baranowski P: Pulmonary toxicity of 1-D nanocarbon materials. Fullerenes Nanotubes. Carbon Nanostruct. 13:141-145, 2005.

Huczko A, Lange H, Calko E, Grubek-Jaworska H, Droszcz P: Physiological testing of carbon nanotubes: are they asbestos like? Fullerene Sci. Technol. 9:251-254, 2001.

Huczko A, Lange H: Carbon nanotubes: experimental evidence for a null risk of skin irritation and allergy. Fullerene Sci.Technol. 9:247-250, 2001.

Jia G, Wang H, Yan L, Wang X, Pei R, Yan T, Zhao Y, Guo X: Cytotoxicity of carbon nanomaterials: single-wall nanotube, multi-wall nanotube and fullerene. Environ. Sci. Technol. 39:1378-83, 2005.

Johnston DE, Islam MF, Yodh AG, Johnson AT: Electronic devices based on purified carbon nanotubes grown by high-pressure decomposition of carbon monoxide. Nat. Mater. 4:589-592, 2005.

Jorio A, Saito R, Hafner JH, Lieber CM, Hunter M, McClure T, Dresselhaus G, Dresselhaus MS: Structural (n, m) determination of isolated singlewall carbon nanotubes by resonant Raman scattering. Phys. Rev. Lett. 86:1118-1121, 2001.

Kagan VE, Tyurina YY, Tyurin VA, Konduru NV, Potapovich AI, Osipov AN, Kisin ER, SchweglerBerry D, Mercer R, Castranova V, Shvedova AA: Direct and indirect effects of single walled carbon nanotubes on RAW 264.7 macrophages: role of iron. Toxicol. Lett. 165:88-100, 2006.

Kam NWS, Dai HJ: Carbon nanotubes as intracellular protein transporters: Generality and biological functionality. J. Am. Chem. Soc. 127:6021-6026, 2005.

Kam NWS, Jessop TC, Wender PA, Dai HJ: Nanotube molecular transporters: Internalization of carbon nanotube-protein conjugates into mammalian cells. J. Am. Chem. Soc. 126:6850-6851, 2004.

Kleiner K, Hogan J: How safe is nanotech? New Scientist. 177:14, 2003.

Klumpp C, Kostarelos K, Prato M, Bianco A: Functionalized carbon nanotubes as emerging nanovectors for the delivery of therapeutics. Biochim. Biophys. Acta 1758:404-412, 2006.

Köhler AR, Som C, Helland A, Gottschalk F: Studying the potential release of carbon nanotubes throughout the application life cycle. J. Cleaner Production 16:927-937, 2008.

Koyama S, Endo M, Kim YA, Hayashi T, Yanagisawa T, Osaka K, Oyama H, Haniu H, Kuroiwa N: Role of systemic T-cells and histopathological aspects after subcutaneous implantation of various carbon nanotubes in mice. Carbon 44:1079-1092, 2006.

Lam C, James JT, McCluskey R, Hunter R: Pulmonary toxicity of single-wall carbon nanotubes in mice 7 and 90 days after intratracheal instillation. Toxicol. Sci. 77:126-134, 2004.

Li Z, Hulderman T, Salmen R, Chapman R, Leonard SS, Young SH, Shvedova A, Luster M, Simeonova PP: Cardiovascular effects of pulmonary exposure to single-wall carbon nanotubes. Environ. Health Perspect. 115:377-382, 2007.

Liu Y, Wu DC, Zhang WD, Jiang X, He CB, Chun TS, Goh SH, Leong KW: Polyethyleniminegrafted multi-walled carbon nanotubes for secure noncovalent immobilization and efficient delivery of DNA. Angew. Chem. Int. Ed. Engl. 44:4782-4785, 2005.

Liu A, Sun K, Yang J, Zhao D: Toxicological effects of multi-wall carbon nanotubes in rats. J. Nanopart. Res. 10:1303-1307, 2008.

Lu C, Su F: Adsorption of natural organic matter by carbon nanotubes. Sep. Purif. Technol. 58:113-121, 2007.

Manna SK, Sarkar S, Barr J, Wise K, Barrera EV, Jejelowo O, Rice-Ficht AC, Ramesh GT: Singlewalled carbon nanotube induces oxidative stress and activates nuclear transcription factor- $\kappa \mathrm{B}$ in human keratinocytes. Nano Lett. 5:1676-1684, 2005.

Maynard AD, Baron PA, Foley M, Shvedova AA, 
Kisin ER, Castranova V: Exposure to carbon nanotube material: Aerosol release during the handling of unrefined single-walled carbon nanotube material. J. Toxicol. Environ. Health Part A 67:87-100, 2004.

Mondal KC, Coville NJ, Witcomb MJ, Tejral G, Havel J: Boron mediated synthesis of multiwalled carbon nanotubes by chemical vapor deposition. Chem. Phys. Lett. 437:87-91, 2007.

Monteiro-Riviere NA, Inman AO: Challenges for assessing carbon nanomaterial toxicity to the skin. Carbon 44:1070-1078, 2006.

Monteiro-Riviere NA, Nemanich RJ, Inman AO, Wang YY, Riviere JE: Multi-walled carbon nanotube interactions with human epidermal keratinocytes. Toxicol. Lett. 155:377-384, 2005.

Moore VC, Strano MS, Haroz EH, Hauge RH, Smalley RE: Individually suspended singlewalled carbon nanotubes in various surfactants. Nano Lett. 3:1379-1382, 2003.

Motta M, Li YL, Kinloch I, Windle A: Mechanical properties of continuously spun fibers of carbon nanotubes. Nano Lett. 5:1529-1533, 2005.

Muller J, Huaux F, Lison D: Respiratory toxicity of carbon nanotubes: how worried should we be? Carbon 44:1048-56, 2006.

Muller J, Huaux F, Moreau N, Misson P, Heiler JF, Delos M, Arras M, Fonseca A, Nagy JB, Lison D: Respiratory toxicity of multi-wall carbon nanotubes. Toxicol. Appl. Pharmacol. 207:221-231, 2005.

Muller J, Decordier I, Hoet PH, Lombaert N, Thomassen L, Huaux F, Lison D, Kirsch-Vloders M: Clastogenic and aneugenic effects of multiwalled carbon nanotubes in epithelial cells. Carcinogenesis 29:427-433, 2008.

Murr LE, Garza KM, Soto KF, Carrasco A, Powell TG, Ramirez DA, Guerrero PA, Lopez DA, Venzor J III: Cytotoxicity assessment of some carbon nanotubes and related carbon nanoparticle aggregates and the implications for anthropogenic carbon nanotube aggregates in the environment. Int. J. Environ. Res. Public Health 2:31-42, 2005.

Murr LE: Microstructures and nanostructures for environmental carbon nanotubes and nanoparticulate soots. Int. J. Environ. Res. Public Health 5:321-336, 2008.

Oberdörster E, Ortiz-Acevedo A, Xie H, Pantano P, Baughman RH, Musselman IH, Draper RK: Exposure of fathead minnow to fullerene and singlewalled carbon nanotubes. J. Soc. Toxicol. 84(S1):325, 2005.

Oberdörster E, Zhu S, Blickley TM, McClellanGreen P, Haasch ML: Ecotoxicology of carbonbased engineered nanoparticles: effects of fullerene $\left(\mathrm{C}_{60}\right)$ on aquatic organisms. Carbon. 44:1112-1120, 2006.

Panhuis MIH: Vaccine delivery by carbon nanotubes. Chem. Biol. 10: 898-899, 2003.

Panyala NR, Eladia MPM, Havel J: Silver or silver nanoparticles: a hazardous threat to the environment and human health? J.Appl. Biomed. 6:117-129, 2008.

Pohanka M, Jun D, Kuca K: Mycotoxin assays using biosensor technology: A review. Drug and Chem. Toxicol. 30:253-261, 2007.

Pulskamp K, Wörle-Knirsch JM, Hennrich F, Kern K, Krug HF: Human lung epithelial cells show biphasic oxidative burst after single-walled carbon nanotube contact. Carbon 45:2241-2249, 2007.

Pulskamp K, Diabate S, Harald F. Krug HF: Carbon nanotubes show no sign of acute toxicity but induce intracellular reactive oxygen species in dependence on contaminants. Toxicol. Lett. 168:58-74, 2007.

Rao GP, Lu C, Su F: Sorption of divalent metal ions from aqueous solution by carbon nanotubes: A review. Sep. Purif. Technol. 58:224-231, 2007.

Sato Y, Motomiya K, Jeyadevan B, Tohji K, Sato G, Ishida $\mathrm{H}$, Hirata $\mathrm{T}$, Hatakeyama R: Effect of cerium ions in an arc peripheral plasma on the growth of radial single-walled carbon nanotubes. J. Appl. Phys. 98:94313-94500, 2005.

Sayes CM, Liang F, Hudson JL, Mendez J, Guo W, Beach JM, Moore VC, Doyle CD, West JL, Billups WE, Ausman KD, Colvin VL: Functionalization density dependence of singlewalled carbon nanotubes cytotoxicity in vitro. Toxicol. Lett. 161:135-142, 2005.

Shvedova AA, Castranova V: Exposure to carbon nanotube material: assessment of nanotube cytotoxicity using human keratinocyte cells. J. Toxicol. Environ. Health Part A. 66:1909-1926, 2003.

Shvedova AA, Kisin ER, Mercer R, Murray AR, Johnson VJ, Potapovich AI, Tyurina YY, Gorelik O, Arepalli S, Schwegler-Berry D, Hubbs AF, Antoini J, Evans DE, Ku BK, Ramsey D, Maynard A, Kagan VE, Castranova V Baron P: Unusual inflammatory and fibrogenic pulmonary responses to single-walled carbon nanotubes in mice. Am. J. Physiol. Lung Cell Mol. Physiol. 289:698-708, 2005.

Smart SK, Cassady AI, Lu GQ, Martin DJ: The biocompatibility of carbon nanotubes. Carbon 44:1034-1047, 2006.

Tamura K, Takashi N, Akasaka T, Roska ID, Uo M, Totsuka Y, Watari F: Effects of micro/nano particle size on cell function and morphology. 
Key Eng. Mater. 254-6:919-22, 2004.

Tian F, Cui D, Schwarz H, Estrada GG, Kobayashi HK: Cytotoxicity of single-wall carbon nanotubes on human fibroblasts. Toxicol. In Vitro 20: 1202-1212, 2006.

Trojanowicz M: Analytical applications of carbon nanotubes: a review. Trends Analyt. Chem. 25:480-489, 2006.

Valcárcel M, Cárdenas S, Simonet BM, MolinerMartínez Y, Lucena R: Carbon nanostructures as sorbent materials in analytical processes. Trends Analyt. Chem. 27:34-43, 2008.

Walters DA, Ericson LM, Casavant MJ, Liu J, Colbert DT, Smith KA, Smalley RE: Elastic strain of freely suspended single-wall carbon nanotube ropes. Appl. Phys. Lett. 74:3803-3805, 1999.

Wang W, Yokoyama A, Liao S, Omori M, Zhu Y, Uo M, Akasaka T, Watari F: Preparation and characteristics of a binderless carbon nanotube monolith and its biocompatibility. Mater. Sci. Eng. C. 7:1082-1086, 2007.

Warheit DB, Laurence BR, Reed KL, Roach DH, Reynolds GAM, Webb TR: Comparative pulmonary toxicity assessment of single-wall carbon nanotubes in rats. Toxicol. Sci. 77:117-125, 2004.

Wei Y, Qiu L, Yu JCC, Lai EPC: Molecularly imprinted solid phase extraction in a syringe needle packed with polypyrrole-encapsulated carbon nanotubes for determination of ochratoxin A in red wine. Intl. Food Sci. Tech. 13:375-380, 2007.

Wick P, Manser P, Limbach LK, DettlaffWeglikowska U, Krumeich F, Roth S, Stark WJ, Bruinink A: The degree and kind of agglomeration affect carbon nanotube cytotoxicity. Toxicol. Lett. 168:121-131, 2007.

Witzmann FA, Monteiro-Riviere NA: Multi-walled nanotube exposure alters protein expression in human keratinocytes. Nanomed. Nanotechnol. Biol. Med. 2:158-168, 2006.

Wörle-Knirsch JM, Pulskamp K, Krug HF: Oops they did it again! Carbon nanotubes hoax scientists in viability assays. Nano Lett. 6:1261-1268, 2006.

Yao Dong-sheng, Cao H, Wen S, Liu Da-ling, Bai Y, Zheng Wen-jie: A novel biosensor for sterigmatocystin constructed by multi-walled carbon nanotubes (MWNT) modified with aflatoxin-detoxifizyme (ADTZ). Bioelectrochemistry 68:126-133, 2006.

Yang M, Kostov Y, Rasooly A: Carbon nanotubes based optical immuno detection of Staphylococcal enterotoxin B (SEB) in food. Intl. J. Food Microbiol. 127:78-83, 2008.

Yang K, Zhu L, Xing B: Adsorption of polycyclic aromatic hydrocarbons by carbon nanomaterials. Environ. Sci. Technol. 40:1855-1861, 2006.

Yu JCC, Lai EPC: Molecularly imprinted polypyrrole modified carbon nanotubes on stainless steel frit for selective micro solid phase pre-concentration of ochratoxin A. Reactive Funct. Polym. 66:702-711, 2006.

Yu MF, Files BS, Arepalli S, Ruoff RS: Tensile loading of ropes of single wall carbon nanotubes and their mechanical properties. Phys. Rev. Lett. 84:5552-5555, 2000.

Zhang MF, Yudasaka M, Koshio A, Iijima S: Thermogravimetric analysis of single-wall carbon nanotubes ultrasonicated in monochlorobenzene. Chem. Phys. Lett. 364:420-426, 2002.

Zeni O, Palumbo R, Zeni L, Sarti M, Scarfi MR: Cytotoxicity investigation on cultured human blood cells treated with single-wall carbon nanotubes. Sensors 8:488-499, 2008. 